\title{
Protein-losing enteropathy in paracoccidioidomycosis identified by scintigraphy: report of three cases
}

Authors

Aline Dayara de Mendonça Berni Erivaldo Elias Júnior ${ }^{1}$ Adalberto Arão Filho ${ }^{2}$ Anamaria Mello Miranda Paniago $^{1}$

${ }^{1}$ Faculdade de Medicina da Universidade Federal do Mato Grosso do Sul, Campo Grande, MS.

${ }^{2}$ Sonimed Nuclear, Campo Grande, MS.
Submitted on: 03/03/2010 Approved on: 05/27/2010

Correspondence to: Anamaria Mello Miranda Paniago

Rua das Paineiras, 68. Bairro São Francisco. Campo Grande-MS, Brazil.

CEP: 79010-070

Phone: +55-67-99120164

Fax: +55-67-33245514

E-mail: anapaniago@

terra.com.br

Source of funding:

Brazilian Department of Science and Technology of the Ministry of Health (DECIT from Portuguese).

We declare no conflict of interest.

\begin{abstract}
Paracoccidioidomycosis (PCM) or South American Blastomycosis is a systemic fungal infection caused by a dimorphic fungus, Paracoccidioides brasiliensis. It represents the most important systemic mycosis in South America and with higher prevalence among male inhabitants of the rural area. PCM usually affects the lungs, and rarely the intestines. The authors report three cases of PCM, treated at the University Hospital of Universidade Federal de Mato Grosso do Sul whose scintigraphy with technetium-99 labeled human albumin revead intestinal protein loss.
\end{abstract}

Keywords: radionuclide imaging; paracoccidioidomycosis; intestinal diseases; Technetium $\mathrm{Tc}^{99 \mathrm{~m}}$ aggregated albumin.

[Braz J Infect Dis 2010;14(5):540-543]@Elsevier Editora Ltda.

\section{INTRODUCTION}

Paracoccidioidomycosis (PCM), also known as South American Blastomycosis or Lutz-Splendore-Almeida disease, is a systemic mycosis caused by the dimorphic fungus Paracoccidioides brasiliensis. It is the most important deep mycosis in Latin America with $80 \%$ of the cases occurring in Brazil. In this country, the disease is endemic in the Southeast, South and Midwest regions, in humid areas with temperate climate, rainy summers, and acidic soil. ${ }^{1-4}$

As the PCM is not a disease that requires compulsory notification, its actual prevalence is unknown. The annual rate of incidence among the Brazilian population has been estimated at 1-3 per 100,000 inhabitants and the mortality rate, at 0.15 per 100,000 inhabitants. ${ }^{4}$ Most affected individuals (90\%) are males, in the age range of 30 to 59 years. ${ }^{3,5}$

Initially, it was hypothesized that the fungus entered the human host through the skin, mucosa and gastrointestinal tract. ${ }^{6-8}$ It is now established that the disease is acquired through inhalation of conidia, with subsequent pulmonary infection. ${ }^{5}$ In the adult-type disease (chronic form), there might be pulmonary involvement, in addition to ulcerated lesions of the skin and mucosa (oral, nasal and gastrointestinal). In children or adolescents, PCM presents as uncommon acute/su- bacute form, known as the juvenile type, mostly affecting the phagocytic-mononuclear system, involving the lymphatic ganglia, spleen and liver and leading to bone marrow dysfunction. ${ }^{3,5,9}$

The intestinal involvement in PCM can affect the mucosa, submucosa and lymphaticabdominal system and is more frequently seen in the acute/subacute form. All segments can be involved, but predominantly affects the jejunum, ileum and proximal portion of the large intestine. Mesenteric ganglion infarction with lymphatic stasis and lymph reflux towards the intestinal lumen were observed in the small and large intestine, leading to an exudative enteropathy. ${ }^{10-13}$

In general, the patient with enteropathy due to PCM presents weight loss, malnutrition, adynamia, abdominal pain, diarrhea and sometimes a palpable abdominal mass. ${ }^{6,14} \mathrm{Hypoalbu}-$ minemia can be severe. ${ }^{13}$

The objective of the present study was to report three cases of PCM in which intestinal protein loss was identified through a scintigraphy with technetium-99 labeled human albumin.

\section{PATIENTS AND METHODS}

The research project called "Clinical Evolution of Paracoccidioidomycosis" was conducted at the Service of Infectious and Parasitic Dis- 
eases of Hospital Universitário da Universidade Federal de Mato Grosso do Sul (UFMS) a state center of reference for the treatment of systemic mycoses. The study was approved by the Committee of Ethics in Research with human subjects of UFMS and the participants that agreed to participate signed an informed consent form. Epidemiological, clinical and laboratory data of the patients with a confirmed diagnosis of PCM were collected during medical consultations. The three patients selected for this case report presented severe hypoalbuminemia with no other apparent loss pathways. They were submitted to scintigraphy in an Elcint scintillation chamber, model SP6-HR, immediately after the intravenous infusion of technetium-99labeled human serum albumin ( $\mathrm{HSA}-\mathrm{Tc}^{99 \mathrm{~m}}$ ). The radioisotope was prepared according to the manufacturer's instructions (IPEN) and the infused dose was $740 \mathrm{MBq}$. The study consisted of two phases, one with dynamic and the other with static images. The dynamic images were acquired in the anterior view of the abdomen, immediately after the administration of the radioisotope, with sequential 30 -second acquisitions, for 45 minutes.

The static images were acquired in the anterior and posterior views of the abdomen, with 700,000 counts, 1,2, 3, 4, 5 and 24 hours after the radioisotope injection.

The HAS- $\mathrm{Tc}^{99 \mathrm{~m}}$ radiotracer presents a uniform distribution in the vascular compartments, being slowly removed from the bloodstream by Kupffer cells from the reticuloendothelial system, so that $75 \%$ to $90 \%$ of the dose is captured by the liver, 3 to $10 \%$ by the spleen and the remainder accumulates in the bone marrow. Hence, the lumen of the intestinal loops is not part of the normal biokinetics of the radioisotope and, therefore, the radioactive activity in the topography of the intestinal loops was considered a positive finding for enteric protein loss.

\section{CASE REPORTS}

\section{Case 1}

A 53-year-old male individual, who was a 45-year-old rural worker from the state of Mato Grosso do Sul, had a diagnosis of PCM in 2001. At the time of the diagnosis, he presented evening fever, weight loss and palpable and painful non-adhered lymph nodes in the axillary and anterior, posterior and lateral cervical regions, with fibroelastic consistency, no inflammatory signs and size varying from $0.5 \mathrm{~cm}$ to $3 \mathrm{~cm}$. The liver was palpable at $3 \mathrm{~cm}$ from the right costal border and the pulmonary and cardiac systems were normal. A lymph node biopsy was performed, of which histological assessment showed to be positive for PCM; yeast-like structures stemming from giant cells characteristic of Paracoccidioides brasiliensis were observed. At the time, the chest X-ray was normal and he presented serum albumin level of $2.60 \mathrm{~g} \%$. Treatment with a combination of trimethoprim/sulfamethoxazole (TMP-SMX) was started; however, as the patient presented a skin rash, it was substituted by itraconazole, used irregularly by the patient. He was lost to follow-up as soon as clinical improvement was obtained.
He returned after three years with a weight loss of $6 \mathrm{~kg}$ and ulcerative lesion of the nose. Serology for PCM, by radial immunodiffusion, was 1:512 and itraconazole $200 \mathrm{mg}$ a day was prescribed. The patient presented initial improvement and did not return to the Service. Two years later, he returned with productive cough, fever, weight loss and adynamia. $\mathrm{He}$ presented hoarseness and a moriform lesion in the soft palate. TMP-SMX was prescribed, but there was little clinical improvement. The patient started to present a cramp-like diffuse abdominal pain, accompanied by aqueous diarrhea. At physical examination, he presented pallor $3+/ 4+$, with painful abdomen at diffuse palpation, ascites, and lower-limb edema $1+/ 4+$. Xray assessment disclosed diffuse nodular interstitial infiltrate. He was submitted to bronchoscopy, that resulted normal and $\mathrm{AFB}$ and fungus cultures and screening in the bronchialalveolar lavage were negative. He was anemic (hemoglobin $=9.8 \%$ ) and erythrocyte sedimentation rate (ESR) was $40 \mathrm{~mm} / \mathrm{h}$. An albumin level of $0.7 \mathrm{~g} / \mathrm{dL}$ showed significant hypoalbuminemia. He was treated empirically for TB with rifampicin and isoniazide and received pyrazinamide and Amphotericin B for PCM, which resulted in the improvement in the medical condition after a two-week treatment, although the albuminemia did not show normalization.

The evolution coursed with the disappearance of the palate lesions, improvement in the fever, coughing and weight loss. There was a decrease in the levels of antibodies in the immunodiffusion for PCM, characterizing clinical remission of the disease. After 7 years of disease evolution and 2 years of regular follow-up, the patient was apparently cured, but presented hypoalbuminemia. The intestinal scintigraphy showed enteric protein loss, probably originating in the large intestine (Figure 1).

Figure 1: Scintigraphy with technetium-99 labeled human albumin, disclosing enteric protein loss, probably originating in the large intestine.

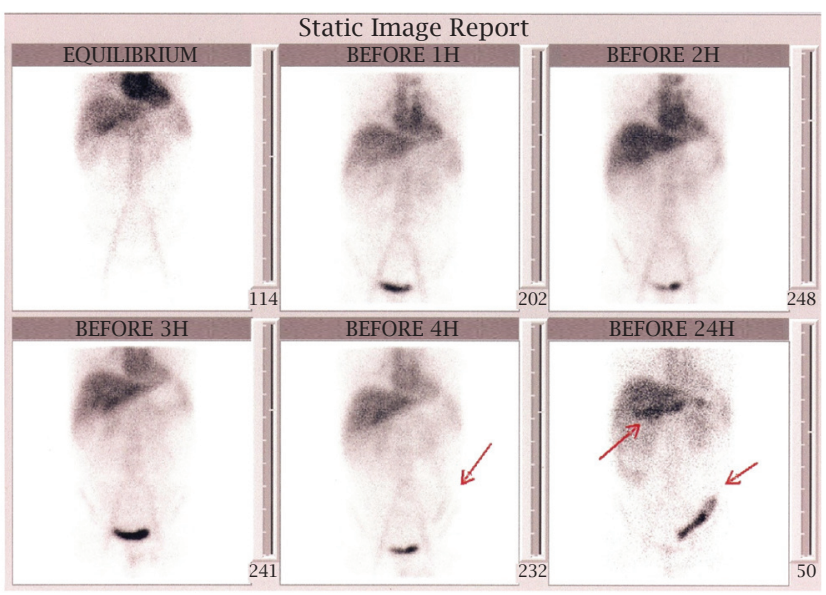




\section{Case 2}

ED, a 36-year-old Elementary School female teacher, native Brazilian from the Indian reserve located in the town of Nioaque state of Mato Grosso do Sul, had a diagnosis of acute/subacute form of PCM when she was 15 years old. In 1990, the clinical examination showed muriform lesions in the oral mucosa and cervical lymphadenomegaly. The lymph nodes were fibroelastic and not tender with the largest measuring $2 \mathrm{~cm}$. She did not present liver or spleen enlargement and the chest X-ray was normal. Brush biopsy of oral lesions disclosed Paracoccidioides brasiliensis. Serological result (immunodiffusion) was 1:64. The patient received TMP-SMX for two years and remission was achieved.

A few months later after treatment withdrawal, in 1992, she relapsed and was admitted to the hospital presenting fever, weight loss, cervical lymph node enlargement, bilateral axillary lymphadenomegaly, hepatosplenomegaly, and jaundice. Treatment was initiated with Amphotericin B. During hospitalization the patient developed ascites and abdominal pain, but was released 60 days thereafter to followed-up as an outpatient. At the last assessment in 2009, the ultrasound scan showed a decrease in liver size, with diffusely heterogeneous and irregular echotexture, slightly dilated portal vein with a mean caliber of $1.3 \mathrm{~cm}$ and a slight splenomegaly, suggesting liver cirrhosis with slight portal hypertension. Aminotransferase levels were normal and serologies for hepatitis $\mathrm{B}$ and $\mathrm{C}$ were negative. Serum albumin had decreased and to $1.8 \mathrm{~g} / \mathrm{dL}$ (reference values: 3.4 to $4.8 \mathrm{~g} / \mathrm{dL}$ ). In relation to possible cause of hypoalbuminemia, 24-hour proteinuria was normal, as well as liver function tests. An intestinal scintigraphy was then performed with technetium-99 labeled human albumin, which demosnstrated protein loss at the colon.

\section{Case 3}

JFM, a 50-year-old male auto mechanic from the town of Terenos, state of Mato Grosso do Sul, was diagnosed with the acute/subacute form of PCM when he was 25 years old. In 1984 he sought our Service after experiencing weight loss $(9 \mathrm{~kg})$, fever and multiform lesions in the gingiva and soft palate, as well as generalized adenomegaly (cervical, epitrochlear, axillary and inguinal sites). The patient complained of abdominal colic-like pain. At physical examination, he presented hepatomegaly $3 \mathrm{~cm}$ from the right costal border. Chest X-ray was normal. Lymph node biopsy followed by histological analysis revealed $P$. brasiliensis. The serology result was $1: 32$. The patient underwent a radiological assessment of intestinal transit, which disclosed an irregular aspect of the mucous intestinal folding pattern, with thickened and discrete folds. Localized intestinal narrowing was also observed. The patient was treated with Amphotericin B. In 1994, he relapsed, with cervical adenomegaly and jaundice. The ultrasonography scan showed a liver with heterogeneous aspect. Treatment with TMP-SMX was initiated followed by clinical remission.

At the last assessment, in 2009, he complained of limb edema; serum albumin was $1.8 \mathrm{~g} / \mathrm{dL}$. Liver function and 24hour urinary protein tests were normal. A scintigraphy with technetium-99 labeled human albumin was performed, which disclosed slight protein loss in the small intestine.

\section{DISCUSSION}

The three reported cases are of acute/subacute PCM or juvenile type, in which the phagocytic-mononuclear system is affected, involving all lymphatic glands and also the liver in the second and third cases. Intestinal involvement is more prevailing in the acute/subacute form, consequent to the involvement of the abdominal/lymphatic system. ${ }^{6,8}$ All patients had been previously treated with clinical remission of the disease.

Persistence of abdominal lymphatic vessel obstruction has been observed even in treated cases. The established fibrosis impairs the lymphatic circulation, causing lymphangiectasia, with lymph reflux to the intestinal lumen, which has been demonstrated by other studies. ${ }^{3,5,9}$

In the assessed patients, the reported digestive complaints were abdominal pain and diarrhea. Digestive complaints are observed in over 50\% of PCM cases: sialorrhea, dysphagia, halitosis, abdominal pain, gastric plenitude, pyrosis and intestinal motility alterations and, less commonly, regurgitation, vomiting, hiccups and the presence of abdominal mass. ${ }^{15}$

The most often affected segments of the gastrointestinal tract are the ileum, stomach, duodenum, jejunum, ascending and descending colon. The functional alterations (hypersecretion, hypotonia and decreased peristaltism) are more frequent than organic abnormal findings (intestinal fold thickening - verified in case 3 through radiological assessment of intestinal transit - stenosis, dilation, extrinsic compression by the liver, spleen or lymph nodes and rigidity). ${ }^{15}$

Intestinal involvement in $\mathrm{PCM}$ is present in $2.7 \%$ to $28.4 \%$ on autopsy. ${ }^{10}$ There can be intestinal absorption impairment of proteins, glucose and, predominantly, fat due to the obstruction of lymphatic pathways. Malabsorption is confirmed through studies of D-xylose absorption and the fecal excretion of fat or labeled albumin. ${ }^{15}$ The abdominal involvement can also be demonstrated by examinations such as intestinal transit, abdominal tomography and colonoscopy. Lesions can occur throughout the small intestine, with consequent acceleration of the intestinal transit, in addition to mucosal hypersecretion and disabsorptive pattern. There is also a predominance of lesions in the terminal ileum, appendix and right hemicolon. In the large intestine predominates mucosal irregularities, followed by loss of haustrations 
interwoven by segmental regions and several stenoses with smooth and regular borders, which at more advanced phases and as a consequence of treatment, become more pronounced due to scarring and fibrosis. ${ }^{16}$

Mesenteric lymph node infarction can be observed in both large and small intestine, with lymphatic stasis and lymph reflux towards the intestinal lumen, thus establishing exudative enteropathy. ${ }^{10-13}$

In the reported cases, the intestinal albumin loss was demonstrated by the scintigraphic method. The study using chromium-51 - labeled albumin in patients with PCM showed a correlation between the intensity of fecal excretion of radioactivity and levels of serum albumin, lymphopenia and presence of fecal fat. ${ }^{17}$

Some authors have used technetium-99 labeled human albumin scintigraphy studies to identify loss of protein through the intestine caused by other etiologies as a qualitative method, as it shows where in the intestine the protein loss occurs. The test is performed in a few hours, with no need for previous preparation or stool collection. It can be used in enteropathy with protein loss due to diseases such as Cröhn's disease, ileocecal tuberculosis and ulcerative colitis. False-positive results can occur in the presence of active intestinal bleeding. ${ }^{18,19}$

At the scintigraphy, cases one and two showed involvement of the large intestine due to PCM as the cause of protein loss and of the small intestine in case three.

The use of scintigraphy with technetium-99 labeled human albumin to demonstrate intestinal protein loss in PCM has been scarcely reported in the literature. A recent study involving ten patients with acute/subacute form disclosed intestinal protein loss in all patients at the time of diagnosis and persistence of the loss years after the treatment in three of them, which demonstrates the importance of the method in the clinical management of these patients. ${ }^{20}$

\section{ACKNOWLEDGMENTS}

To the Department of Science and Technology of the Brazilian Ministry of Health (DECIT) for the financial support.

\section{REFERENCES}

1. Fornajeiro N, Maluf ML, Takahachi G, Svidzinski TI. [Paracoccidioidomycosis epidemiological survey using gp43, in two cities of northwestern region of Parana, Brazil]. Rev Soc Bras Med Trop 2005; 38(2):191-3.

2. Marques SA, Franco MF, Mendes RP et al. [Epidemiologic aspects of paracoccidioidomycosis in the endemic area of Botucatu (Sao Paulo - Brazil)]. Rev Inst Med Trop Sao Paulo 1983; 25(2):87-92.
3. Paniago AM, Aguiar JI, Aguiar ES et al. [Paracoccidioidomycosis: a clinical and epidemiological study of 422 cases observed in Mato Grosso do Sul]. Rev Soc Bras Med Trop 2003; 36(4):455-9.

4. Coutinho ZF, Silva D, Lazera M et al. Paracoccidioidomycosis mortality in Brazil (1980-1995). Cad Saude Publica 2002; 18(5):1441-54.

5. Shikanai-Yasuda MA, Telles Filho FQ, Mendes RP et al. [Guidelines in paracoccidioidomycosis]. Rev Soc Bras Med Trop. 2006; 39(3):297-310.

6. Andrade ALSS. Paracoccidioidomicose linfático-abdominal. Contribuição ao seu estudo. Revista de Patologia Tropical 1983; (12):165-256.

7. Machado-Filho J, Miranda JL. Considerações relativas à blastomicose sul-americana. Localizações, sintomas iniciais, vias de penetração e disseminação em 313 casos consecutivos. Hospital (Rio de Janeiro) 1960; (58):99-137.

8. Brass K. [Observations on the pathologic anatomy, pathogenesis, and evolution of paracoccidioidomycosis]. Mycopathol Mycol Appl 1969; 37(2):119-38.

9. Blotta MH, Mamoni RL, Oliveira SJ et al. Endemic regions of paracoccidioidomycosis in Brazil: a clinical and epidemiologic study of 584 cases in the southeast region. Am J Trop Med Hyg 1999; 61(3):390-4.

10. Chojniak R, Vieira RA, Lopes A et al. Intestinal paracoccidioidomycosis simulating colon cancer. Rev Soc Bras Med Trop 2000; 33(3):309-12.

11. Fonseca LC, Mignone C. [Paracoccidioidomycosis of the small intestine. Radiologic and anatomo clinical aspects of 125 cases]. Revista do Hospital das Clinicas 1976; 31(3):199-207.

12. Magalhaes A. [Paracoccidioidomycosis (South American blastomycosis). Radiological aspects]. Revista do Hospital das Clinicas 1980; 35(3):147-55.

13. Laudanna AA, Bellen BV, Bettarello A. South American blastomycosis as a cause of malabsorption and protein-losing enteropathy. Arq Gastroenterol 1975; (25):83-90.

14. Daher RR, Vasconcelos WM, Cardoso VM. Fígado e blastomicose sul-americana. J Bras Med 1973; (25):83-90.

15. Mendes RP. Paracoccidiodomicose (Blastomicose Sul-Americana). Quadro Clínico. In: Focaccia R., ed. Veronesi: tratado de infectologia. 3 ed. São Paulo: Atheneu 2005; pp. 1381-8.

16. Negro GBD, Gonçalves EG. Paracoccidiodomicose (Blastomicose Sul - Americana). Diagnóstico Laboratorial e Radiológico. In: Focaccia R., ed. Veronesi: tratado de infectologia. 3 ed. São Paulo: Atheneu 2005; pp. 1389-95.

17. Troncon LEA, Martinez R, Meneghelli UG et al. Perda intestinal de proteína na paracoccidioidomicose. Rev Hosp Clin Fac Med S Paulo 1981; 172-8.

18. Hildebrand P, Henze E, Lietzenmayer R, Schoetensack M. Localization of enteral protein loss by $99 \mathrm{~m}$-technetium-albuminscintigraphy. Eur J Nucl Med 1989; 15(4):217-8.

19. Oommen R, Kurien G, Balakrishnan N, Narasimhan S. Tc$99 \mathrm{~m}$ albumin scintigraphy in the localization of protein loss in the gut. Clin Nucl Med 1992; 17(10):787-8.

20. Griva BR, Mendes RP. Scintigraphic evaluation of enteric protein loss in patients with active paracoccidioidomycosis. Biomédica 2008; 28(suppl):149. 